\title{
INTEGRATING GRADUATE ATTRIBUTES INTO A MASTER OF DIVINITY PROGRAMME AT A SOUTH AFRICAN UNIVERSITY
}

\author{
I. A. Nell* \\ Practical Theology \\ e-mail: ianell@sun.ac.za
}

\section{J. P. Bosman*}

Centre for Learning Technologies

e-mail: jpbosman@sun.ac.za

*Stellenbosch University

Stellenbosch, South Africa

\section{ABSTRACT}

Stellenbosch University promotes generic graduate attributes (GAs) as an integral part of its teaching and learning strategy en route to curriculum renewal. The Faculty of Theology targeted the Master of Divinity programme to become the pilot project for implementing GAs as part of a process of programme renewal and held a number of workshops for implementation. The conceptual framework for the research drew on, Cultural Historical Activity Theory. The main research question was: What are the conceptions of lecturers concerning the integration of graduate attributes into a Master of Divinity programme after participation in a process of curriculum renewal? The study entailed semi-structured interviews and the data of the 16 interviews were analysed through qualitative analysis. The curriculum renewal strategy contributed positively to the lecturers' conceptions of the integration of GAs into the Master of Divinity programme. The gendered and diverse cultural-historical context of the participants (and the students) strongly informed the conceptions of the lecturers. These findings are important for curriculum renewal in the light of cultivating critical and responsible citizenship.

Keywords: graduate attributes, curriculum renewal, activity theory, Master of Divinity programme, cultural-historical activity theory, teaching and learning strategy

\section{INTRODUCTION}

The Faculty of Theology at Stellenbosch University (SU) participated in a project on critical citizenship between 2012 and 2013. ${ }^{1}$ In 2013, the Faculty also became involved in the university’s project on graduate attributes (GAs), as part of an initiative related to signature learning that started in 2011 (Jacobs and Strydom 2014). The project was initiated by the Centre for Teaching and Learning, and was part of the strategic initiatives of the university in the planning cycle for 2013-2018. ${ }^{2}$ After three workshops during 2013, in which representatives 
from all 10 faculties of the university participated, it was decided that the GAs should be integrated into the programmes and modules of all the different faculties. At the Faculty of Theology, the decision was made to use the Master of Divinity (MDiv) ${ }^{3}$ programme for this purpose. Already at the end of 2013, the first workshop was held at the Faculty of Theology to plan for this integration, and during the course of 2014, two follow-up workshops were held with all the lecturers involved in the programme to work on the implementation of the GAs into the different modules of the course. This article reports on the process of curriculum renewal through the two workshops and the ensuing conceptions of lecturers regarding the integration of GAs in the curriculum towards cultivating critical and responsible citizenship.

Concerning the concept of GAs, SU's Strategy for Teaching and Learning (2014-2018) describes the GAs in the following way: 'an enquiring mind', 'an engaged citizen', 'a dynamic professional' and 'a well-rounded individual' (Stellenbosch University 2013, 6-7). The strategy also indicates what teaching in terms of these GAs should entail, namely 'critical and scholarly lecturers', 'engaging curriculum design', 'dynamic delivery' and 'an enriched campus experience' (Stellenbosch University 2013, 7-8). It is specifically the first two GAs (an enquiring mind and an engaged citizen) that have a direct connection with the topic of this article. Both critical citizenship and GAs relate to SU's HOPE Project (www.thehopeproject.co.za), which aims to develop a university response to the poor and rural communities and the continuing historical problems of the $20^{\text {th }}$ century and to 'embrace the challenges of the $21^{\text {st }}$ century, the new generations of young people, new ways of learning, new opportunities for research and the exploitation of developing technology' (Matieland 2010, 10). According to the late rector of the university, Prof. Russel Botman, SU wants to be a multiracial university working with a pedagogy of hope, aiming at an Afrocentric approach to higher education (Botman 2007).

As strategic vehicle for the process of integrating GAs into the MDiv programme, two workshops were held (February and October 2014). The purpose of the workshops was to create an opportunity to reflect on the why and how of the integration of GAs into the MDiv programme and to see in what ways critical citizenship could also be cultivated through curriculum renewal.

During the first day of Workshop 1, the group spent time on asking the why questions regarding integrating GAs with inputs on the institutional initiative (including historical background and clarification concerning the conceptual framework) and aligning the university's GAs to the already existing programme-specific profile of students entering ministry. The second day of Workshop 1 was spent on asking the how questions concerning the 
integration of GAs, with specific reference to the different modules that make up the MDiv and how the curriculum, pedagogy and specifically assessment could be transformed. The process included lecturer presentations on modules that have already been renewed through the integration of learning technologies, which formed a sub-theme of the workshop. Essentially, the main aim of the workshop was for the lecturers to reflect on the potential of integrating GAs into the curriculum, pedagogy and assessment of their modules and how learning technologies could support this transformational renewal of the curriculum.

Workshop 2 continued the thread of Workshop 1 and focused more on the teachinglearning aspects of curriculum redesign. The focus was on more specific ideas for how one could integrate GAs, and the group was guided through (re)design processes, as well as thinking though their different curricula as three broad discipline groups.

The purpose of this article is to examine the conceptions of lecturers regarding the integration of GAs into an MDiv programme, at SU en route to curriculum renewal.

The primary research question was:

What are the conceptions of lecturers concerning the integration of graduate attributes into a Master of Divinity programme after participation in a process of curriculum renewal?

The secondary research questions that flowed from the main question were:

1. What does the activity system look like when focused on the current MDiv curriculum (the object) with the aim of transforming said curriculum through the integration of graduate attributes (the outcome)?

2. What are the main themes (including contradictions) regarding integrating graduate attributes into the MDiv curriculum?

3. What are the conceptions of lecturers after taking part in the process of changing the MDiv curriculum through the integration of graduate attributes towards cultivating critical citizenship?

To answer these questions, the article takes the following route: After a short literature review on the intersection between GAs, activity theory (AT), critical citizenship and programme renewal in theology, the theoretical framework for the research, namely cultural-historical activity theory (CHAT), is described and contextualised to the MDiv programme as activity 
system. Thereafter, the methodology is explained, after which the main findings, limitations and conclusions are presented.

\section{LITERATURE REVIEW}

Regarding the integration of GAs at SU, the work of Simon Barrie (2006; 2007) played an important role. According to Barrie $(2007,440)$, '[t]he four increasingly complex, qualitatively distinct understandings of generic attributes as outcomes are described as: 1 . Precursor Conception; 2. Complement Conception; 3. Translation Conception; 4. Enabling Conception’. The first two are seen as additive, while the last two are more transformative. Jacobs and Strydom $(2014,66,71)$ studied a signature learning experience project at SU (which was the pre-cursor to the GA project reflected on here) and came to the conclusion that the initiative was underpinned by a complement conception and was therefore additive and that ultimately these kinds of supplementary initiatives that are not integrated into the curriculum hamper its success. They also make it clear (drawing on Millar 2012; see also Jones 2013) that the concept of generic attributes is problematic and that one should look towards GAs that are 'aligned to knowledge' (Jacobs and Strydom 2014, 72). Jones (2013, 602) makes a broader critical point when she says: 'Graduate attributes policy has often been implemented without a careful consideration of the contextual basis within which it is positioned'.

Regarding the integration of GAs into theological higher education curricula, one finds literature referring to the ways in which profiles for students who want to enter ministry in different denominations are used in developing these curricula. An example of work that has been done in this regard is the use of student profiles in some Reformed denominations at different South African universities (see Burger and Nell 2012, 17-32; Kritzinger 2012, 3347).

With regard to using CHAT as a framework in studying programme renewal or GAs, there is the example of Kizito (2015, 219), who used CHAT as a framework for the implementation of an extended curriculum programme in the Faculty of Science at the University of the Western Cape (UWC), noting that it deepened the understanding of the process through providing a conceptual map, accommodating all participants and providing a holistic institutional activities view. Mashiyi (2015) reports on another example from UWC where CHAT and authentic learning were used to understand the implementation of a foundation programme for a commerce degree programme. It was found that CHAT (working in concert with authentic learning) is a useful heuristic, leads to student-centred teaching and lays the foundation for generic GAs (Mashiyi 2015, 176-177). Jones (2013, 602) used AT in looking at GAs and 
suggests that there is nothing generic about GAs and that analysing with an AT lens uncovers 'the multiple dimensions of graduate attributes and in doing this provides an interpretive space within which these dimensions can be explored and hence outlines a new structure for the theorising of graduate attributes'.

With regard to curriculum renewal through critical citizenship education the work of Costandius and Bitzer $(2015,5)$ helped the researchers to understand the challenges related to curricula renewal in the South African context, where the expectation is that the curricula should be more sensitive to communities and constituents outside universities. This so-called 'critically engaged' curricula address public accountability within an increasingly differentiated South African higher education system. These insights also link to the cultural historical aspects of Activity Theory. The contribution of Waghid $(2015,127)$ in extending critical citizenship education beyond the critical in making an argument for responsibility takes the argument even further by placing emphasis on the fact that critical citizenship education 'requires that one offers an account of what the practice means' (Waghid 2015, 127).

This review helps us to have a sharper (and more careful) focus when using CHAT as framework for investigating the integration of GAs into a theology programme, namely the MDiv. It is to the CHAT framework that we now turn.

\section{THEORETICAL FRAMING}

The choice of CHAT as conceptual framework for the research in this study relates to the fact that it is a theory that in a comprehensive way provides concepts to describe activities and processes, consisting of so-called teaching-learning environments and teaching-learning interactions, of the participants in the process (Ashwin 2012, 51). The historical roots of the theory go back to insights from Leont'ev (1979) and Vygotsky (1978) that were later further developed by Engeström (1987; 2001) and became known as CHAT (Faasen 2016, 70-73; Hardman and Amory 2015, 14-18). Although the theory developed from the background of development psychology, it was later expanded to include processes of human development in order to analyse and describe the relations between individuals and groups in different domains of teaching and learning and on different levels of complexity (Kizito 2015, 213).

One of the fundamental assumptions in using CHAT is that all human interaction is mediated. According to Vygotsky (1978) there are two types of mediation, namely external tool-mediated labour and internal sign-mediated psychological activity. According to Engeström (2001, 137), contradictions are an important aspect of CHAT and there will always be 'historically accumulating structural tensions within and between activity systems'. Kizito 
(2015, 219) is however of the opinion that these group of tensions must not be viewed in a negative light, but must be pursued for possible areas of growth.

The most important contribution of CHAT as a theory, concerning the process of the integration of GAs into a specific programme, relates to the analysis of the relations between teaching-learning environments and teaching-learning interactions (Ashwin 2012, 69) and as such, using CHAT as a theoretical framework to study the processes of curriculum change is a good alignment.

When CHAT is used as a theoretical framework in research on the teaching-learning environment (and often programmes or modules), it is, according to Ashwin (2012, 55-56), important that the researcher defines what he/she understands concerning the activity system. The activity system in other words stands in the centre of the research project.

Regarding the research in this study, the focus was on the activity system of lecturers (subject) who engage in the problem space of an MDiv programme (object), with the aim to potentially renew/transform the curriculum by integrating GAs through the mediation of a GA framework, two workshops as part of a process of curriculum redesign, and the potential of using learning technologies in a blended learning pedagogical approach (mediating artefacts/tools). Surfacing the interactions and interdependencies between the different aspects of this activity system provides valuable insights regarding the experience of the participants in the process as well as the tensions caused by participation.

Although we are conscious of the fact that the focus of the research unfortunately did not allow the possibility to gain a better understanding of the 'interaction' taking place between the lecturers and the students within the teaching-learning environments concerning the integration of GAs (Ashwin 2012, 56), it was important in a first phase of the research project to gain deeper insight into the perspectives of the lecturers concerning their participation in the workshops and their subsequent conceptions of integrating GAs into the MDiv programme. In the next phase of the project it will be necessary to include both lecturers and students, which naturally will lead to the interactions of more activity systems and also cause the heightening of the complexity of the interaction, as argued by Engeström (2001).

With regard to the integration of GAs into the MDiv programme at the Faculty of Theology at SU with the goal of renewing the curriculum, the activity system could be represented as in Figure 1. 


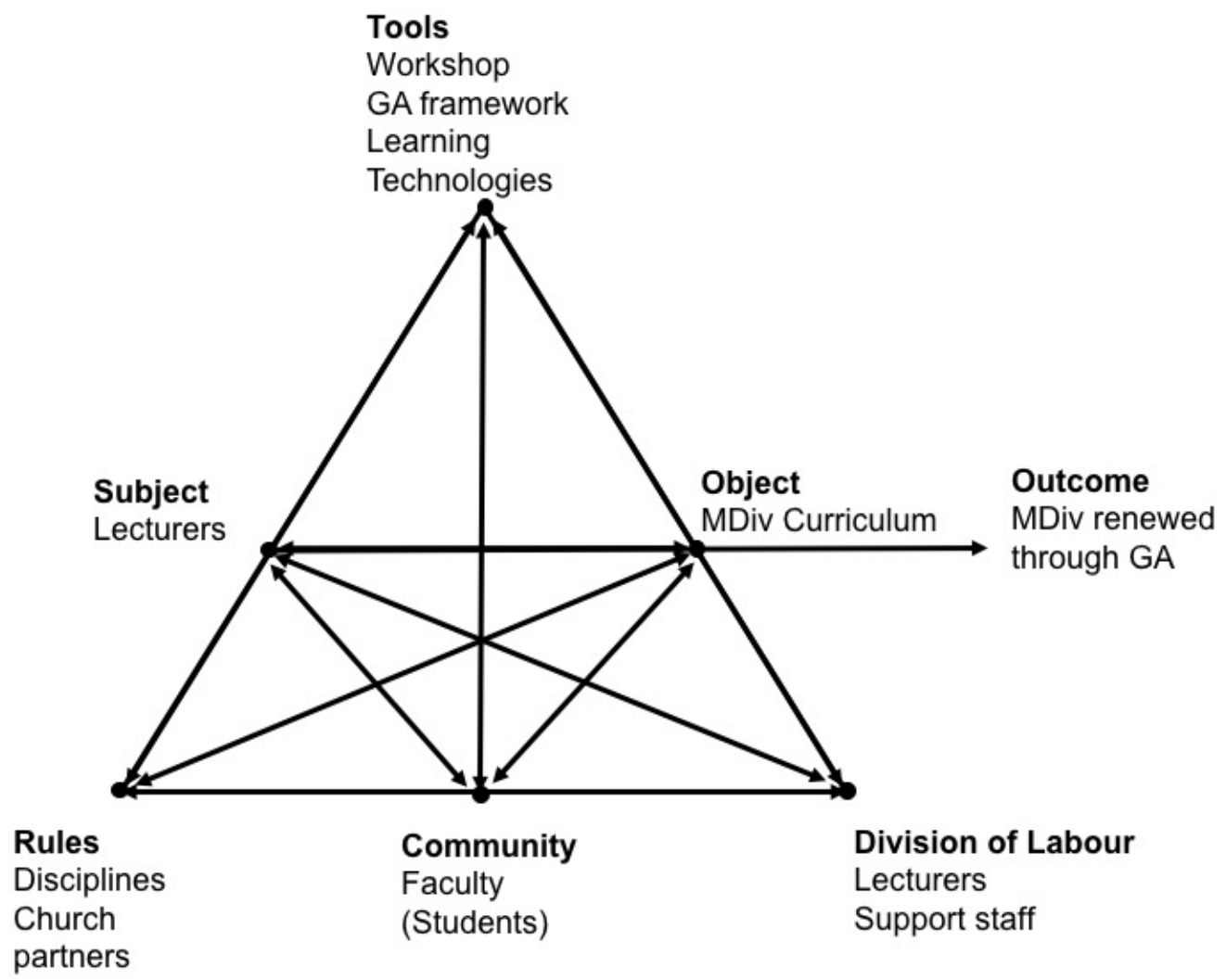

Figure 1: Activity system of the process of integrating GAs into the MDiv programme

Following Hardman and Amory (2015, 18; see also Hardman 2015) and Ashwin (2012, 5354), we can therefore describe the activity system of the process of integrating GAs into the MDiv curriculum as follows.

- The subject is the lecturers as a group whose point of view was chosen for analysis.

- The object is the MDiv curriculum, which is the problem space where the activity of integrating GAs into the MDiv curriculum is shaped into the outcome.

- $\quad$ The outcome is the renewal or transformation of the MDiv through the integration of Gas towards cultivating critical and responsible citizenship.

- $\quad$ The tools used for mediating the shaping process are the instruments of workshops as a chosen process for curriculum renewal, graduate attributes as a framework for curriculum renewal and learning technologies, which potentially support a renewed curriculum through a blended learning pedagogy.

- $\quad$ The community that shares the common object, i.e. the MDiv curriculum, includes both the lecturers and the students of the faculty.

- $\quad$ The division of labour includes the horizontal division of activity between lecturers as 
well as the possible vertical division between lecturers and support staff in the faculty and the university.

- The rules that implicitly or explicitly constrain the actions within the activity system are the academic disciplines and the church partners who (as external professional body) have a stake in the curriculum.

Apart from describing the nodes, the activity system as a collective whole with a 'multitude of voices that can be in conflict with each other', which can lead to contradictions that have the potential to lead to development and change in the activity system (Ashwin 2012, 55; Faasen 2016, 89-92), was used as an analytical lens.

In short, the reason why CHAT is a relevant theoretical framework for this study is because AT is in its core practice-based and asks the researcher to become involved in the activities of the subjects (Faasen 2016, 94). As researchers we were involved in the activity system as subjects and as such, a next phase for the research could be to move the activity system into a deliberate developmental process of generating a cycle of expansive learning through what has come to be known as a change laboratory process (Hardman and Amory 2015, 16).

\section{METHODOLOGY}

Purposive sampling was used, which entailed that the participants that were selected were supposed to suit the investigation. This is in keeping with a qualitative research approach where 'issues related to defining the overall populations are generally treated as part of purposive sampling, which inherently requires an explicit definition of the kinds of data sources that are of interest’ (Morgan 2008, 800).

The potential participants were chosen by asking most of the lecturers attending the workshop to answer some semi-structured questions during personal interviews (22 lecturers in total; 16 participating in the interviews). Ethical clearance was obtained beforehand from SU's ethics committee and each participant signed a consent form. After anonymising the recorded interviews through transcription, we used Atlas.ti for a qualitative inductive thematic analysis with CHAT as a theoretical framework. The following questions were posed in the semistructured interviews to the participants:

1. Did your participation in the process of GA integration changed your thoughts about GAs?

2. What role did your participation in the workshops and the model we used play in your thoughts and acts? 
3. Did your practices change?

4. Since the first workshop, did you make any changes to your teaching and learning practice?

5. Do you experience any tension or uncertainty concerning the implementation of GA's in your teaching?

In the analysis of the data we decided to relate the different components of CHAT to the answers of the five questions to see in what ways the responses reflected the specific aspects of the activity system under scrutiny.

\section{FINDINGS}

We identified three main themes regarding the conceptions of lecturers concerning the integration of GAs into an MDiv programme after participation in the process of curriculum renewal:

- Workshop process as mediating tool

- $\quad$ Graduate attributes as framework for curriculum renewal

- $\quad$ Cultural-historical context.

\section{Theme 1: Workshop process as mediating tool}

From the data it strongly emerged that the process of curriculum renewal through two workshops that were held in February and October 2014 played an important role in the conceptions of lecturers. Many participants described the process as providing a space for thinking and reflection, and remarked that the collaborative mode of working with colleagues was a key element in the process. The way in which the workshops tried to facilitate an integrated process of thinking through how GAs can be embedded or enacted in the MDiv's different modules was appreciated. One of the main outcomes of the workshop was that it gave the participants a new language to talk about the MDiv curriculum in a new way.

Two quotations from the data support these remarks:

The workshop helped us on different levels, especially creating consciousness concerning the concepts. I mean, people are talking about it and suddenly it became part of our grammar. (Quote 4:14, translated from Afrikaans)

To tell the truth, it was only at the workshop that I really came to understand what this is all about and also how one can link the GAs with outcomes of one's modules and different ways of teaching and assessment. So far the workshop helped me in that way - to conceptualize and to understand the implications for the way that I teach, assess, etc. Yes, in that sense it meant a lot. (Quote 7:1) 
As we were expecting in this kind of analysis, there were also contradictions and tensions and some participants had a more ambiguous feeling about the process. The following two quotes serve as example:

In a workshop environment sometimes people feel left behind or perhaps not heard, or ... because they are not getting on board with a particular platform or a way of instruction, that perhaps they are not valued or their style of input is not valued. (Quote 1:18)

Yes and no ... I'll start with the yes in that it sparked me to rethink what we currently have in terms of the theology and development stuff in the MDiv and say, is this really what's needed? So in that way, yes, but having said that, where I previously worked we were very big on graduate attributes and they were very similar. I had already started doing that ... when I taught at an undergraduate level I'd already started aligning my outcomes with graduate attributes, which then eventually looked at assessment. So for me it wasn't a new concept, but within this context it caused me to look at what theology and development [were] offering and now make a change for next year. (Quote 2:12)

One can sense that although the introduction of GAs and the emphasis on integration are important, one can easily exclude and leave people behind who experience exclusion from the discourse or feel that their style of teaching is not being valued. On the other hand, one finds people for whom the concepts are not new and maybe also not so inspiring.

\section{Theme 2: Graduate attributes as framework for curriculum renewal}

The next number of responses also relate to the framework of GAs that (according to our activity system) served as mediating artefacts or tools. From the number of responses in the data, one could sense that the GAs were in the centre of interest and categorising the codes took quite some time.

The GAs were found to be a useful concept, although there were some that had a reserved opinion. As in the workshops, the discovery of the GA framework was akin to discovering a new enabling language. Throughout the interviews the SU-specific GAs (enquiring mind, engaged citizen, dynamic professional and well-rounded individual), seen as part of the formal and informal curriculum and professional profile, were well represented.

There were, however, some contradictions as well. The most prominent tension was that almost none of the subjects mentioned the attributes that the academics at SU should try to develop in themselves. The attribute of criticality did come through, but mainly the focus was on developing the GAs for the students in the MDiv. The other tension that surfaced was a devaluing of the GAs as part of a higher education programme - should GAs be taught at university?

Once again, some quotes from the data show in what ways the GAs helped the participants 
as a useful concept and as a framework:

So in other words, what you try to learn here are the same attributes that you have to give the people with whom you work. And if you can do that, it means you are rounded off as a professional pastor-academic and you can do these things. (Quote 15:26)

It [GAs] helps me to structure what I am teaching and to say, okay - if you want well-rounded students then you want to expose them to different things and what will be the kind of things that you want to expose them to and reflecting on them. I find it very creative - so, yes it really works for me. (Quote 4:2, translated from Afrikaans)

In general it was a good process for me because it links with my natural way of thinking, concentrating more on content than [on] presentation. So, for me it was a good process to reflect on the GAs, after you have done your preparation - how do you integrate them. I know there are dangers concerning the idea of only concentrating on a student-centred approach ... but it strengthened the point for me - that is that you do have to reflect on teaching and learning at the same time. (Quote 5:1, translated from Afrikaans)

From the quotes concerning the use of GAs as a framework for reflection on teaching and learning activities, one can sense that it really helped the lecturers to think in new and creative ways about that with which they are busy. Concerning the contradictions and tensions, see the following quotes as examples:

We shouldn't force it. We should actually be saying, if we're doing one or we've got two, some will have three, that's wonderful, but not every module is going to assess all these attributes and therefore your outcomes. (Quote 1:27)

I am not sure whether one could interpret the GAs as outcomes - you find it all over, across a student's academic career - you can't pinpoint it. For example: I realised that some students struggle to formulate an argument and sometimes cannot ask a simple question because they are not used to it. They are used to the repetition of concepts and copying - but do not want to reflect critically .... I think it is because they are on different levels and I think the GAs is a challenge in the MDiv - it might even help with new ways of assessment. (Quote 2:16)

From these quotes it is clear that the tensions and contradictions caused the lecturers to comment on not forcing the integration of GAs, asking whether they can function as outcomes and whether it is at all possible to pinpoint them and use them for assessment purposes.

\section{Theme 3: Cultural-historical context}

Given the nature of CHAT and the importance of the social in activity systems, this theme that surfaced is not surprising.

The data point to three aspects regarding the context within which the activity system of integrating GAs into an MDiv programme functions. Firstly, gender discourse is seen as important; secondly, the MDiv activity systems (from the view of both lecturer as subject and 
student as subject) contain a very rich diversity in terms of representing an African, international and South African mosaic of different cultures, economic status, (English) language proficiency and religious affiliation; and thirdly, a partnership between students and the faculty is important, keeping mind that students come differently prepared to the MDiv (which begs the question why GAs are not introduced earlier in the undergraduate offering of the faculty).

Quotes from the data show a rich diversity of perspectives from the lecturers and although the role of the students constitutes a separate activity system, some reflection on their role as part of the cultural-historical context reveals a rich mosaic:

Obviously proficiency in the English language is one of the things that we need to assess, but in terms of the sequence of importance, should that be the gateway in theology? And at a certain stage it has to be, because they have to hand in a piece of work that has to be polished and well worked out. But at the beginning of the year when I'm wanting them to begin to think theologically and school them into the discipline, then knowledge is far more important than articulation. So having the opportunity to say, actually, don't work it out, write me a report and speak to me from your report. (Quote 7:11)

We have a conversation with somebody who is totally different in terms of your denomination and in terms of other religions, speaking to Muslim students out there. So a critical aspect there is issues of diversity, the content and the process and so on. (Quote 15:33)

It is different from what I experience in the USA when I lectured on gender - with 20 students in class, 18 women and 2 men. Now I find this rich diversity, white, black, brown. It is unbelievable - and most of them come from strong patriarchal backgrounds - some of them from very traditional communities, making it a huge challenge. (Quote 16:22, translated from Afrikaans)

I think the other side of it is also just, we are in a well-resourced environment, so having access to things like SUNLearn and knowing that students can get a podcast or see a video clip that I've uploaded for them, or can make reading material available or have a discussion forum, those are incredible gifts to have. (Quote 7:5)

From these quotes one gets an impression of the rich diversity of topics and themes addressed here. Diversity and differences concerning language, religion, gender and the role of resources are all part and parcel of the cultural-historical factors that influence the integration of GAs into the MDiv programme.

Some of the contradictions and tensions already surfaced, but the following quote gives some insight into the underlying tension in a topic such as teaching on gender:

There was this one very critical student that continuously pointed to the fact that we only concentrated on manhood. I realised how ideologically loaded the situation is - we hesitate to speak about women and poverty and many times only concentrate on the role of men. But in so many of the courses we only concentrate on the role of men and therefore to have a course where we specifically focus on the experience of women helps a lot. It is not always easy, many of the students do not want that. (Quote 16:12) 
Summarising the data under the category of cultural-historical aspects, one can sense the rich diversity of perspectives contributing towards ways in which it is very easy to exclude some voices and minority groups and challenging the way we think and reflect on the integration of GAs into the programme.

\section{CONCLUSIONS}

In the conclusion we return to the research question asked in the beginning:

What are the conceptions of lecturers concerning the integration of graduate attributes into a Master of Divinity programme after participation in two workshops?

From the themes that emerged from the data one could formulate the following responses:

'The process of curriculum renewal through GAs contributed positively to the lecturers' conceptions regarding the integration of GAs into the MDiv programme.' The process which was enacted through workshops was experienced as a successful tool that mediates the shaping of the object (the MDiv programme) towards an outcome of renewal of the curriculum through the integration of GAs into the programme.

Closely aligned to the process is 'the graduate attributes framework itself, which we can safely say is potentially a very useful mediating tool' for an activity system (such as the one we studied) looking at curriculum (object) in which the outcome is renewal or transformation of the curriculum towards critical and responsible citizenship. The GAs themselves interact with the subjects' (lecturers') relation (i.e. conceptions) to the object (MDiv programme). They do also create contradictions, but as Hardman and Amory $(2015,19)$ state: 'Surfacing contradictions enables one to see where transformation in the system or between systems is likely to occur'.

This more accepting and maybe even transformational stance to the GAs from the MDiv lecturers shows a slight development from the Jacobs and Strydom (2014) findings on GAs in the SU context. It might be that because the GAs have been 'translated' or at least 'synchronised' to the existing outcomes of the MDiv; they are not (at least not at first glance) seen as too generic and therefore powerless for transformation. We think they therefore could be conceptualised as more transformational and indeed closer aligned to the knowledge domain of this MDiv programme.

'The finding that the gendered and richly diverse cultural-historical context of the lecturers (and the students) strongly informs the conceptions of the lecturers' should be taken seriously. 
Future processes (e.g. a change laboratory) should keep in mind that the contextual diversity, and also very real tension that only surfaced in this study, might become a strong torrent of emotion or resistance that could create further insurmountable contradictions between the different aspects and actions of the activity system. This brings us to a last response.

In the data there was some evidence that spoke more deeply to the not-yet visualised context of the activity system (i.e. rules, community and division of labour). Most of the findings above relate to the more visible activities of subject, tool, object, outcome and of course a strong cultural-historical presence. Yet our contention is that this is potentially a very deep well of insight into how lecturers deal with the conception of integrating GAs into a curriculum at the Faculty of Theology at SU. The relationship between the three main disciplines and between the faculty and the church partners (rules) and the way in which that impacts on how the integration of GAs is viewed has potential. In the same way, a focus on the community of the faculty and the broader university community (lecturers, students and support staff) as well as the horizontal and vertical division of labour could also enrich our understanding of this complex human endeavour of changing a curriculum.

The insights of Waghid $(2015,127)$ in arguing for the extension of critical citizenship education beyond the critical by focusing on responsibility also open up a new way of understanding the role of GA's in developing educational curricula. Drawing on the work of Derrida's $(2004,91)$ seminal idea of responsibility in understanding it as 'a summons requiring a response' Waghid $(2015,128)$ relates the idea of citizenship education to responsibility and states: 'responsible citizenship education ought to engender understandings that students should be encouraged to take risks coupled with giving and account of their citizenship'. Where GA's serve this goal in curriculum renewal one could find a situation where 'responsible citizenship education can encourage students to take risks to do the improbable' $(2015,128)$.

With regard to the secondary research questions, we managed to: (1) construct a representation of an activity system that aims to transform an MDiv programme through the integration of GAs; (2) identify three strong themes with corresponding contradictions; and (3) show that the plan to use workshops for the process of curriculum redesign was instrumental as the choice of a mediating tool for this activity.

Future research could include using third-generation CHAT to also represent the activity system of students as subject and how it interacts with the activity system of lecturers as subjects in terms of the object of the MDiv curriculum (Ashwin 2012, 63-64; Hardman and Amory 2015, 16-17). It could also entail placing the outcome of the activity system, for example renewal of the MDiv curriculum through the integration of GAs, into a developmental 
generative process of expansive learning through something such as a change laboratory process.

\section{NOTES}

1. As part of the critical citizenship project, an interdisciplinary group conducted qualitative empirical research through focus group interviews. A number of lecturers and students were identified and semi-structured interviews were held in two focus group meetings concerning the respondents' perceptions of critical citizenship, and the ways in which and places where they see the notion operative in the programmes and curricula of the faculty (Costandius et al. 2015).

2. This is known as the Stellenbosch University Institutional Intent and Strategy 2013-2018 and is described in the following way: 'This Institutional Intent and Strategy 2013-2018 takes cognisance of and supports the proposed outcomes of the global development goals and the National Development Plan of South Africa. The country will be a better place if we tackle the challenges of the 21st century in the spirit of 'making hope happen'. The University's commitment to serving society has since 2007 found expression in the HOPE Project, and 'creating hope' has been recognised as the institution's footprint in South Africa, on the continent of Africa and internationally' (Stellenbosch University 2013, 11).

3. In the 2015 Yearbook of the Faculty of Theology, the programme is described in the following way: 'The MDiv in Church ministry offers training to ministers, clergy, pastors, lay workers, pastoral care givers and pastoral therapists for the ministry. The programme is designed to equip people professionally for the ministry' (Faculty of Theology 2015, 32).

\section{REFERENCES}

Ashwin, P. 2012. Analysing teaching-learning interactions in higher education: Accounting for structure and agency. London: Continuum.

Barrie, S. C. 2006. Understanding what we mean by the generic attributes of graduates. Higher Education 51(2): 215-241.

Barrie, S. C. 2007. A conceptual framework for the teaching and learning of generic graduate attributes. Studies in Higher Education 32(4): 439-458.

Botman, H. R. 2007. A multicultural university with a pedagogy of hope for Africa: Installation speech. www.sun.ac.za/university/Management/rektor/docs/russel\%20installation\%20speech.pdf (accessed 19 May 2016).

Burger, C. and I. Nell. 2012. Ministerial formation in the Dutch Reformed churches: In search of new paradigms. In Between the real and the ideal: Ministerial formation in South African churches, ed. M. Naidoo, 17-32. Pretoria: Unisa Press.

Costandius, E., M. Blackie, B. Leibowitz, I. Nell, R. Malgas, S. O. Rosochacki and G. Young. 2015. Stumbling over the first hurdle? Exploring notions of critical citizenship. In The Palgrave handbook of critical thinking in higher education, ed. M. Davies and R. Barnett, 545-558. New York, NY: Palgrave Macmillan.

Costandius, E. and E. Bitzer. 2015. Engaging higher education curricula: A critical citizenship perspective. Stellenbosch: Sun Press.

Derrida, J. 2004. Eyes of the university: Right to philosophy 2. Transl. J. Plug et al. Stanford: Stanford University Press.

Engeström, Y. 1987. Learning by expanding: An activity-theoretical approach to developmental research. Helsinki: Orienta-Konsultit Oy.

Engeström, Y. 2001. Expansive learning at work: Toward an activity theoretical reconceptualization. Journal of Education and Work 14(1): 133-156. 
Faasen, M. 2016. A learning design framework for active learning using audience response systems. DPhil Thesis, Stellenbosch University, Stellenbosch.

Faculty of Theology. 2015. Yearbook of the Faculty of Theology. Stellenbosch: Stellenbosch University.

Hardman, J. 2015. Chatting about CHAT. Presentation at a postgraduate seminar at the University of the Western Cape.

Hardman, J. and A. Amory. 2015. Introduction to cultural-historical activity theory and tool mediation. In Activity theory, authentic learning and emerging technologies: Towards a transformative higher education pedagogy, ed. V. Bozalek, D. Ng’ambi, D. Wood, J. Herrington, J. Hardman and A. Amory, 9-21. London: Routledge.

Jacobs, C. and S. Strydom. 2014. From 'Matie' to citizen - graduate attributes as signature learning at Stellenbosch University. The Independent Journal of Teaching and Learning 9: 63-74.

Jones, A. 2013. There is nothing generic about graduate attributes: Unpacking the scope of context. Journal of Further and Higher Education 37(5): 591-605.

Kizito, R. 2015. Structuring an activity theory-based framework for evaluating a science extended curriculum programme. South African Journal of Higher Education 29(1): 211-237.

Kritzinger, K. 2012. Ministerial formation in the Uniting Reformed Church in Southern Africa: In search of inclusion and authenticity. In Between the real and the ideal: Ministerial formation in South African churches, ed. M. Naidoo, 33-47. Pretoria: Unisa Press.

Leont'ev, A. N. 1979. The problem of activity in psychology. In The concept of activity in Soviet psychology, ed. J. V. Wertsch, 21-39. Armonk, NY: Sharpe.

Mashiyi, N. 2015. Case study 13.4: Understanding the implementation of curriculum innovation from an activity theory perspective. In Activity theory, authentic learning and emerging technologies: Towards a transformative higher education pedagogy, ed. V. Bozalek, D. Ng'ambi, D. Wood, J. Herrington, J. Hardman and A. Amory, 173-177. London: Routledge.

Matieland. 2010. Ambitious HOPE Project gives direction for the next decade. Stellenbosch: Stellenbosch University. www.myvirtualpaper.com/doc/stellenbosch-University/matieland_ 2010_ 1_eng/2010082702/\#12 (accessed 19 May 2016).

Millar, B. 2012. Graduate attitudes (not attributes) in emergency medical science students. Paper presented at WILRU Ten-Year Anniversary Conference, Cape Town.

Morgan, D. L. 2008. Sampling. In The Sage Encyclopedia of Qualitative Research Methods, ed. L. M. Given, Vol. 1 \& 2, 799-800. Los Angeles, CA: Sage.

Stellenbosch University. 2013. Strategy for Teaching and Learning (2014-2018). www0.sun.ac.za/ ctl/wp-content/uploads/2013/02/SU-STRATEGY-FOR-TL-2014-2018.docx (accessed 19 May 2016).

Vygotsky, L. S. 1978. Mind in society: The development of higher psychological processes. Cambridge, MA: Harvard University Press.

Waghid, Y. 2015. Coda: Beyond critical citizenship education. In Engaging higher education curricula: A critical citizenship perspective, 123-130. 